\title{
Influence of Psychological Qualities on the Efficiency of Competitive Activity of Basketball Players at the Initial Stage of Sport Skills Formation
}

\author{
Dr. Salman Hani Roumie
}

\begin{abstract}
This study aims at presenting the effects of psychological qualities and properties of personality on the efficiency of young sportsmen's competitive activity. Through the psychological training of basketball players gradual increase of sport skill will be achieved.
\end{abstract}

Keywords-Basketball, Competitive Activity, Psychological Qualities.

\section{INTRODUCTION}

$\mathrm{R}_{\mathrm{t}}^{\mathrm{s}}$ EGULARITIES of both preceding and subsequent training stages must be taken into account at each stage of sporting perfection within the system of training of basketball players - physical, technical and tactical, and especially psychological. Achievement of high sport results depends on initial preparation, when physical and psychological basis of the special capacity is created. Leading sports psychologists $[8,10,11]$ who study general psychological training of a sportsman as teaching process say that due to the purposeful formation of psychical processes and properties of personality, their development is accelerated and the formation of the special movement skills becomes more effective, which promotes their competitive activity in future $[1,2,3,9]$.

The analysis of literature shows that the problems of influence of psychological qualities and properties of personality on the efficiency of young sportsmen's competitive activity has not yet been sufficiently studied until now. There are some researches that touched upon the problems of importance of specific psychological properties of personality with respect to the playing line in basketball when presenting different technical and tactical methods of game, determining separate psychological properties of the players for comparing them to those of the sportsmen of other sports $[4,5,6,7]$.

At the same time, reasonable structure of psychological preparation of young sportsmen based on the knowledge of influence of psychological qualities and properties of personality on efficiency of competition activity of basketball players at the stage of perfection of sport skills is obviously important for optimization of the training and competition

Associate Professor, Lebanese University, Lebanon. process management and allows to define the means and methods of accounting and controling during the sportsmen's training.

\section{AIM, TASKS, MATERIALS AND RESEARCH METHODS}

The aim of this study is determining the level of development and importance of psychological qualities and properties of sportsmen's personality of initial qualifying groups that determine the efficiency of competitive activity of basketball players at the stage of sporting skills formation.

\section{Research tasks:}

1. Defining psychological qualities and properties of the personality assisting formation of sporting skill in basketball.

2. Defining correlation of the determined psychological qualities and properties of sportsman's personality with the parameter of efficiency of competitive activity of basketball players of initial qualifying groups.

Research methods: analysis of research and methodical literature, pedagogical supervisions, pedagogical testing, psychological testing, methods of mathematical statistics. The studies were conducted at the initial period. Sixty-five basketball players of different qualification, including beginners of $3^{\text {rd }}$ and $2^{\text {nd }}$ athletic class, were included in the study.

\section{RESEARCH RESULTS}

Questioning of leading coaches of master teams and the analysis of research and methodical literature on psychology of sport and sporting games were carried out to determine the psychological qualities and properties influencing the sport skills formation of basketball players. It has allowed finding psychological parameters which help maintain psychological and mobilization stability under the extreme conditions of competitive activity. It was especially important to set those psychological qualities and properties which are the most stable (personality) and thus, the most meaningful for formation of stability of competitive activity.

Typological features of higher nervous activity of sportsmen, features of cognitive sporting thinking, perception, brief memory, attention, emotional volitional sphere (selfcontrol and development of volitional qualities, operative 
estimation of actual functional states), level of sportsmen's self - appraisal and self-attitude, degree of expressed self-appraisal to the confidence processes were defined in this study.

Cross-correlation analysis which allows defining the correlation of manifestation level of psychological characteristic with the results of pedagogical testing of basketball players of initial qualifying groups was carried out to study the influence of psychological qualities and properties of personality on efficiency of competitive activity.

Ten psychological parameters were determined in beginners that had reliable cross - correlation with the results of pedagogical testing $(\mathrm{p}=0.05)$ : decisiveness, time of the operative and tactical thinking, generality and expressiveness of volitional qualities of persistence and insistence; expressiveness of volitional qualities of self-control and self mastery, mobility of nervous processes; specialized perception of time without implementation of any actions, adequacy of perception of temporal intervals while implementing actions up to $15 \mathrm{sec} ., 30 \mathrm{sec}$. each above factor has only one reliable connection with the results of the pedagogical testing, and only index of exactness of perception of temporal interval $15 \mathrm{sec}$. has two reliable connections, namely, the number of basketball hoop hits in the game $(\mathrm{r}=0.56)$, and by the result of foul shots $(\mathrm{r}=0.43)$.

The above psychological factors correlate with all results of pedagogical testing except for "protective actions". The most high cross-correlation connection for beginners in basketball is determined between the number of basketball hoop hits and index of generality of volitional qualities of persistence and insistence $(r=0.57)$. The parameter of time of the operative thinking has tight connection with the index of exactness of foul shots $(r=0.49)$. The same level of connection $(r=0.49)$ has the index of time of the tactical thinking with the percent of basketball hoop hits in the game.

Thus, on the basis of the determined cross-correlation between different psychological and pedagogical factors, it can be supposed that above 10 psychological qualities and properties of personality are the basis for sport skills formation of beginners in basketball.

In the group of basketball players of 3rd athletic class the cross- correlation connection of 2 psychological parameters was set with the results of pedagogical testing $(p=0.05)$ : indexes of confidence in ordinary vital functions and decision; time of the tactical thinking; visual - motor reaction; errors of reaction of choice of two and three factors; braking force; balance of nervous processes, features of external and internal tense attention; stability, exactness, errors and concentration of attention; volume, errors of information processing; efficiency of the logical memorizing; factor of self - attitude: self confidence, self-leading, self - perception, internal conflict; specialized perception of time without implementation of any actions. Up to 10 of 18 presented factors correlate with the results of the " $8 \times 28$ run" test. As in the previous group, the parameter "Protective moving" has no reliable connection with the presented psychological qualities and properties of personality, for the basketball-players of the group 4 indexes of psychological qualities that each has 2 reliable connections with the indexes of such pedagogical tests have been set: "Foul shots" and the "8x28 run". It is the efficiency of logical memorizing $(r=0.68$ and $r=0.77)$, stability of attention $(r=$ 0.68 and $\mathrm{r}=0.61)$; simple visual motor reaction $(\mathrm{r}=0.79$ and $\mathrm{r}$ $=0.58)$; time of the tactical thinking $(r=0.59$ and $r=0.71)$. The highest cross - correlation connection has been set between the factor of self-attitude - self - confidence and by the results of the "8x28 run" test. Certain interest is presented by the circumstance that from all researched properties of attention the following have reliable connections with pedagogical tests: efficiency of attention is connected with the percent of basketball hoop hits $(r=0.56)$; exactness and errors of attention with implementation of "8x28 run" test $(r=0.65$ and $r=0.67)$. In addition, it should be noted that from all 12 indexes of the specialized perception of time just 1 is certainly related to the index of pedagogical test: efficiency of attention with the index of exactness of hit of ball $(r=0.56)$, exactness and errors of attention correlate with the "8x28 run" test $(r=$ 0.65 and $r=0.67)$. In addition, from all 12 indexes of the specialized perception of time only one for certain is related to the pedagogical parameters. It is the index of the specialized perception of time without implementation of actions up to 10 sec. the results of the "Hoop shoot" test $(r=-0.66)$. The presented materials allow concluding that amount of psychological indexes and level of their cross - correlation connection with pedagogical tests for the basketball players of 3rd athletic class are considerably higher, than those of beginning sportsmen.

The most of personality's psychological qualities and properties for certain correlating with the results of pedagogical tests was determined for the basketball players of 2nd athletic class (at $\mathrm{p}=0.05$ ).

There have been educed 39 psychological indexes, having coefficients of correlation scope from $r=0.52$ to $r=0.84$. It is personality anxiety; self-appraisal of own sporting achievements; confidence in the situations of competitive activity, in ordinary vital functions and decision; emotional aspect of the psychological state, characterizing the mood; expressed of volitional aspect of the psychological state, characterizing the mood; expressed of volitional qualities of boldness and decision, insistence and persistence; generality and expressiveness of volitional qualities of independence and initiative; errors and time of the tactical thinking: time of reaction of choice of 2 stimuli from 3 signals, level of functional mobility of nervous processes; force of process of excitation; features of narrow effective attention; volume, speed, concentration and errors of switching the attention; specific, abstract and emotional type of perception; brief memory; efficiency of the logical memorizing; factors of self attitude - self - confidence, self - leading, expected attitude of the other, self - attachment, self - acusation, specialized perception of time at implementation of actions up to $30 \mathrm{sec}$; adequacy of perception of temporal intervals without implementation of actions up to $30 \mathrm{sec}$., $60 \mathrm{sec}$. and at implementation of actions up to $30 \mathrm{sec} ; 2$ indexes of psychological qualities that each has 3 reliable cross correlation to connection. It is, foremost, the index of expressed volitional qualities to initiative and independence, that has reliable connections with the indexes of tests "Foul 
shot" ( $\mathrm{r}=0.54)$, "8x28 run" $(\mathrm{r}=0.61)$, "Protective moving" $(\mathrm{r}$ $=0.73)$.

The most cross - correlation dependence among all parameters was set between the specific type of perception and the "Protective moving" test $(\mathrm{r}=0.84)$. Research results have shown that except for the operative thinking, practically all factors of psychological qualities and properties have reliable connections with the pedagogical tests of this group of basketball players; in particular, all factors of confidence, processing of information. Tactical thinking and all types of perception are for certain related to the indexes of pedagogical tests. So, for example, the confidence we examine from 3 positions: firstly, the confidence in the situation of competitive activity has cross - correlation connection with the number of basketball hoop hits $(r=0.71)$; secondly, the confidence in ordinary life is related to " $8 \times 28$ run" test $(r=0.71)$; thirdly, the decisiveness is related to the "Foul shot" test $(r=0.65)$. It can be supposed on the basis of the stated psychological qualities and properties of sportsmen's personality, that the psychological basis of the special sporting activity of basketball players are founded during the sport skills forming at the level of 2 nd athletic class.

\section{CONCLUSION}

1. The study allowed to determine important psychological qualities and properties of the personality influencing efficiency of competitive activity of young basketball players at the stage of sport skills formation.

2. The gradual increase of amount of psychological qualities and properties from 10 in beginners and up to 30 in the basketball players of 2 nd athletic class are evidence of:

- Increase of importance of psychological training of basketball players at the initial stage of sport training;

- Gradual increase of importance of optimal level of development and manifestation of the determined psychological qualities and properties with the increase of sport skill.

\section{REFERENCES}

[1] Adler A. individual psychology / A. Adler // History of foreign psychology: Tests / Edited by P. Ya.Galperin, A.N Zhadan. M. 1986. $256 \mathrm{p}$.

[2] Asmolov A.G. Psychology of personality / Asmolov A.G// M., 1990. $288 \mathrm{p}$.

[3] Akhmed O.O. Effectiveness of activity of handballers of different line of business depending on properties of personality: candidate's dissertation of psychology sciences/ akhmed Oribi Oda. GTs OLIFK. - M. 1984 $158 \mathrm{p}$.

[4] Golub Ya. V. Psychological testing in sporting practice/ Ya. V. Golub, P.V.Bunzen// First international science congress. St. - Peterburg. 2003. - Vol. 2 - P. 18 - 20.

[5] Korobeynikov G.V. the research of psychology states appearing in sports activity / V. G. Korobeynikov, G. V. Rossokha, L.D. Konyayeva// physiol.journal. Kyiv. 2006 - 52, N 2 - P. 203.

[6] Ilyin, Ye, P. psychology of sport/ Ye.P.Ilyin//Spb.: Piter, 2008. - 352 p.

[7] Kozina Zh.L.. Display of conformities to law of development of the self - organized systems in the field of sports games/ Zh. L.Kozina// Pedagogics, psychology and medical - biological problems of physical education and sport - Kharkiv: KhSAPC, 2006, - N 12. - P. 70 - 78.

[8] Psychological training of a sportsman: Works of institutes of physical education/ Edited by P.A. Rudik, A. Ts. Puni. - M.: Physical Edcation and sport, 1965.
[9] Borg G. psychophysical bases of perceived exertion / G. Borg // Med. And Science in Sport and Expert, 1982. - N 5. V. 1 - P. 332 - 337.

[10] Cafarelli E. psychological contribution of the perception of effort / F. Cafarelli// Med. Sci. Sport and Exerc. 1989. V. 14,2, pp 387 - 389.

[11] Okudo H. Dynamics of the basketball shot with application to the free shot / H. Okudo, M. Hubbard// Journal of sports Science. - 2006. Volume 24. - Issue 12. - pages 1303 - 1314. 